\title{
Fatal work related injuries in agricultural production and services to agriculture sectors of New Zealand, 1985-94
}

\author{
S Horsburgh, A-M Feyer, J D Langley
}

\begin{abstract}
Objectives-To describe work related fatal injuries to agricultural workers in New Zealand to identify priority areas for further research and injury control measures.

Methods-Injury deaths in New Zealanders aged 15-84 inclusive for the period 1985-94 were identified and the coroner's files for these obtained. These files were then reviewed to determine whether the death arose as a result of work activities. Those deaths considered to be work related were coded for information relating to decedent demographics and the circumstances of the fatal injury. Work related deaths from injury occurring in the agricultural production and services to agriculture sectors were analysed.
\end{abstract}

Results-The rate of fatal injuries to male agricultural workers over the study period was $21.2 / 100000$, with injury deaths in the agricultural sectors accounting for nearly a quarter of all work related fatal injuries in New Zealand in that time. There was no significant decline in fatal injuries to agricultural workers in the study decade. Workers in the 65-84 age bracket were at substantially higher risk of fatal injury than other age groups. Machinery and motor vehicles were commonly associated with fatal injury, with overturns on or next to embankments and slopes being the most frequent scenario.

Conclusions-The results of this study highlight fatal injuries in older workers and machinery incidents (particularly tractors overturning) as priority areas for further research into contributing factors and injury control measures.

(Occup Environ Med 2001;58:489-495)

Keywords: agriculture; fatal injury

The agricultural workforce represents a distinctive challenge to injury control researchers and practitioners. The hazards faced by agricultural workers are many and varied, and the tasks performed by them are likewise diverse. Long hours of work are commonplace, often within tight time schedules and economic restraints, and work often involves the use of equipment and machinery which has high potential for inflicting serious harm. The workforce is widely dispersed geographically and a considerable minority of workers are employed on a casual basis or move regularly from one workplace to another. ${ }^{12}$

Given these points, it is not surprising that workers in the agricultural sector are consistently found to be one of the highest risk groups for fatal occupational injury. Overseas studies in North America, Australia, and the United Kingdom place Agriculture in the top four industries for fatal injury. ${ }^{3-7}$

The situation in New Zealand seems similar to that found overseas. Studies investigating work related fatal injury in New Zealand have found that workers in agricultural occupations face greatly increased risk of fatal injury compared with the all industry average. ${ }^{89}$ The most recent study covering the period of 1985-94 showed that 116 male workers in animal production occupations were fatally injured during work activities, yielding a rate of $17 / 100000$ worker-years. This was over three times the rate of all occupations combined. ${ }^{9}$ Clearly, fatal injury to workers in the agricultural sector represents an important area for further investigation.

Recent information available on fatal injuries in the agricultural sector of New Zealand has either lacked the detail needed for more than an overview of the fatal injuries, or has been derived from agencies which have been shown to have poor capture. ${ }^{10}$ The New Zealand work related fatal injury study (WRFIS) ${ }^{9}$ created a dataset extracted from the coroner's records for all work related fatal injuries in New Zealand over the decade 1985-94. The WRFIS dataset provides a uniquely rich and complete source for information on fatal injuries in New Zealand during that period, with much better capture of cases than all other sources combined. ${ }^{10}$

This paper aims to capitalise on the strengths of the WRFIS to describe the numbers, rates, and trends of these fatal injuries in the agricultural sectors by employment, age, type of incident, and nature of injury. These analyses are intended to provide a basis for targeting further research and injury control efforts in the agricultural sectors of New Zealand.

\section{Methods}

\section{DATA ACQUISITION}

Cases were selected from a dataset of all work related fatal injuries in New Zealand for the decade 1985-94. Details of how this dataset was created are described in detail elsewhere. ${ }^{9}$ Briefly, the coroner's record was requested for each death recorded in the New Zealand 
Health Information Service (NZHIS) mortality database (a dataset containing all recorded deaths in New Zealand) as having an international classification of diseases ninth revision (ICD-9) external cause of injury (E-code) between E800 and E989 and being within the age range of 15-84 years (inclusive) at time of death. Deaths coded with an E-code of E810-E819 (motor vehicle traffic accidents), E870-E876 (medical misadventure), E878E879 (surgical complications), E930-E949 (adverse drug reactions), and E950-E959 (suicide) were excluded at this stage. Of the requested coroner's records, $96.8 \%$ were obtained for review. The remaining files were either missing or incorrectly linked with the NZHIS database. Records from other agencies such as the Accident Compensation Corporation (ACC), the Occupational Safety and Health Service $(\mathrm{OSH})$, and specific industry agencies were also searched to ensure the widest possible capture of work related fatal injuries in New Zealand throughout the study period.

Requested coroner's records were reviewed to assess whether the fatal injury was work related, resulting in a dataset of 741 cases. Further details on the criteria used for this assessment can be found in Feyer et al. ${ }^{9}$

Every unnatural death in New Zealand is legally required to be referred to a coroner, who decides whether to hold an inquest into the circumstances surrounding that death. Death due to injury is by definition unnatural; therefore, a coroner's record should exist for every fatal injury. In the coronre's records reviewed for the WRFIS, $86.5 \%$ had a police statement included, $70.9 \%$ contained at least one witness statement, and $83.3 \%$ had a postmortem report attached. Interestingly, only $51.8 \%$ contained an official OSH inspection report. This may be due to the low capture of work related fatal injuries by this agency. ${ }^{10}$ Because they include data obtained from many sources, coroner's records generally represent a rich source of information for determining the nature and circumstances surrounding a death from injury.

Cases were coded for various decedent demographics (including age, sex, employment, occupation at time of injury, and industry sector in which they worked) and injury event details (including nature of injury, agency of injury, type of incident, mechanism of injury, and location). All injury event details, except type of incident, were coded according to slightly modified versions of the Australian National Occupational Health and Safety Commission type of occurrence coding schemes. ${ }^{11}$ Type of incident was classified according to the groupings of ICD-9 E-codes published by the National Institute of Occupational Safety and Health. ${ }^{4}$ The current New Zealand standards for coding industry and occupation were used. ${ }^{12} 13$

ANALYSIS

Cases for this study were a subset from the entire work related fatal injuries database selected on the basis of industry sector. The
Australia and New Zealand standard industrial classification ${ }^{13}$ was used to subset fatal injuries which occurred in the agricultural production (category A01) and services to agriculture (category A021) sectors. These categories specifically exclude forestry, fishing, and hunting and trapping. Fatal injuries which occurred on a farm but to a person not engaged in agriculture were also examined, but were excluded from the main analyses due to low numbers and the lack of an accurate denominator.

Rates, with 95\% confidence intervals (95\% CIs), were calculated with labour force figures from the 1986, 1991, and 1996 New Zealand censuses as the denominator. The number of people working full time or part time in a paid or unpaid capacity in agricultural production and services to agriculture sectors for each census year was obtained, and a linear function used to estimate the number of workers in these sectors for the years between censuses. All workers were weighted equally, regardless of the number of hours worked, in both the numerator and denominator of the rate calculations.

Because of the low number of fatal injuries to women and their substantially lower risk compared with men, the analyses reported are for male workers only. Combining the female workforce with that of the male workforce would increase the denominator term of rate calculations by around $30 \%$ while contributing little to the numerator term.

The $\chi^{2}$ statistic was used to analyse trend and differences between rates when sufficient numbers were available. The $95 \%$ CIs were calculated with the method described in Armitage and Berry ${ }^{14}$ for proportions.

\section{Results}

For the decade 1985-94, there were 159 workers of 15-84 years of age inclusive in the agricultural production and services to agriculture sectors who were fatally injured in work related incidents. This represents $21 \%$ of all work related fatal injuries in New Zealand for that period. An additional nine cases were found where contractors employed in capacities not specific to agriculture were fatally injured on a farm. These cases, which included landscapers and earthmoving contractors, were excluded from further analyses. A further three cases, in which the fatal injury occurred on a farm, contained insufficient information to determine an appropriate sector, and were also not included in the subsequent analyses.

Nearly all fatal injuries occurred in men. Although the low number of female workers fatally injured during the study period precludes detailed analyses, it is interesting to note that all seven of them were working with animals at the time of their injury. The remainder of the results deal only with male workers.

Overall, the rate of fatal injury/100 000 male worker-years was 21.2 for both sectors combined. Although most $(n=123,81 \%)$ injuries occurred in the agricultural production sector, the rate was significantly lower than in the services to agriculture sector $\left(\chi^{2}=33.92, \mathrm{df}=1\right.$, 
Table 1 Number and rate/100000 worker-years (95\% CI) of fatal injury by sector and decedent characteristics, 1985-94, (note that figures for employment and age only include men)

\begin{tabular}{|c|c|c|c|c|c|c|c|c|c|}
\hline & \multicolumn{3}{|c|}{ Agricultural production } & \multicolumn{3}{|c|}{ Services to agriculture } & \multicolumn{3}{|c|}{ Total } \\
\hline & $n$ & Rate & $95 \% C I$ & $n$ & Rate & $95 \% C I$ & $n$ & Rate & $95 \% C I$ \\
\hline \multicolumn{10}{|l|}{ Sex: } \\
\hline Male & 123 & 18.4 & 15.3 to 22.0 & 29 & 57.6 & 38.6 to 82.7 & 152 & 21.2 & 17.9 to 24.8 \\
\hline Female & 7 & 2.2 & 0.9 to 4.6 & 0 & 0.0 & 0.0 to 17.9 & 7 & 2.1 & 0.8 to 4.3 \\
\hline \multicolumn{10}{|c|}{ Employment status: } \\
\hline Self employed & 71 & 17.4 & 13.6 to 21.9 & 17 & 74.9 & 43.2 to 120.7 & 88 & 20.5 & 16.4 to 25.2 \\
\hline Employee & 52 & 20.1 & 15.0 to 26.3 & 12 & 52.4 & 29.0 to 87.0 & 64 & 22.2 & 17.1 to 28.4 \\
\hline \multicolumn{10}{|l|}{ Age: } \\
\hline $15-24$ & 14 & 12.9 & 7.1 to 21.6 & 8 & 71.4 & 30.8 to 140.6 & 22 & 18.4 & 11.5 to 27.8 \\
\hline $25-34$ & 22 & 14.5 & 9.1 to 22.0 & 4 & 30.4 & 8.3 to 77.7 & 26 & 15.8 & 10.8 to 23.2 \\
\hline $35-44$ & 27 & 17.2 & 11.3 to 25.1 & 8 & 69.0 & 29.8 to 136.0 & 35 & 20.8 & 14.5 to 28.9 \\
\hline $45-54$ & 22 & 18.3 & 11.5 to 27.7 & 6 & 67.9 & 24.9 to 147.6 & 28 & 21.7 & 14.4 to 31.4 \\
\hline $55-64$ & 19 & 21.6 & 13.0 to 33.7 & 2 & 42.3 & 5.1 to 152.6 & 21 & 22.6 & 14.0 to 34.6 \\
\hline $65-84$ & 18 & 42.0 & 24.9 to 66.3 & 1 & 119.3 & 3.0 to 662.7 & 19 & 43.5 & 26.2 to 67.8 \\
\hline
\end{tabular}

$\mathrm{p}=0.000)$. The rates of fatal injury for self employed workers and employees in both sectors were similar $\left(\chi^{2}=0.56, \mathrm{df}=1, \mathrm{p}>0.050\right)$.

Most $(n=104,85 \%)$ fatal injuries in the agricultural production sector occurred to workers in market oriented animal producer occupations (NZSCO category 612), with a further 12 $(10 \%)$ deaths occurring in market farmers and crop growers (NZSCO category 611). The distribution of occupations in the services to agriculture sector was less clustered, with $10(35 \%)$ workers in the aircraft controllers and technicians group (NZSCO category 314) and eight $(28 \%)$ in agricultural, earthmoving, and other material equipment operators (NZSCO category 833).

Rates of fatal injury by age group are shown in table 1 . Note that, unlike the other age groups, the 65-84 category encompasses 20 years. This has been done to allow sufficient numbers for stable estimates of the rates to be calculated. For both sectors combined, there is a slight increase in rates with age up to the 65-84 age group, where the rate rises drastically $\left(\chi^{2}=13.13, d f=5, p=0.022\right)$. This pattern is echoed in the rates for the agricultural production sector. The rates for the services to agriculture sector tended to fluctuate widely because of low numbers, making interpretation difficult.

Table 2 shows a breakdown of the number and rate for each of the agricultural sectors by year of fatal injury. Although the rate of fatal injury for both sectors combined seems to show marked fluctuations, this variation was all within the limits expected by chance $\left(\chi^{2}=5.46\right.$, $\mathrm{df}=9, \mathrm{p}>0.050$ ).

Machinery incidents dominated both sectors, making up over $50 \%$ of all incidents (table 2 ). This was particularly evident in the 65-84 age group in the agricultural production sector, where the rate of machinery incidents was nearly three times that for all age groups combined. By contrast, workers aged 15-24 in that sector had a rate of machinery incidents half that for the combined age groups, although machinery incidents were still the leading incident type for this age group. There was no significant trend for machinery incidents across the study decade $\left(\chi^{2}=0.86, \mathrm{df}=1, \mathrm{p}>0.050\right)$.

Of the 79 machinery incidents, 56 (71\%) were related to tractors (52 (93\%) of which were in the agricultural production sector).
Thirty five $(63 \%)$ of these incidents related to tractors involved the tractor overturning about its horizontal axis, with 29 (83\%) occurring while the man who died was operating the tractor on or near an embankment or slope. A further seven $(13 \%)$ of the incidents related to tractors occurred when the man who died fell from the tractor and was hit by the tractor or a tractor implement. There was no significant trend in the rates of incidents with tractors across the study period $\left(\chi^{2}=0.02, \mathrm{df}=1\right.$, $\mathrm{p}>0.050$ ).

Fourteen of the 79 incidents with machinery $(18 \%)$ occurred when the man who died was operating other forms of mobile machinery such as bulldozers and graders. Again, a large proportion (nine, $(64 \%)$ ) of these incidents occurred while the man who died was operating the machinery on or near an embankment or slope (eight, $(89 \%)$ of these were overturn events). In total, $44(56 \%)$ of all machinery incidents occurred while operating on or near an embankment or slope.

Motor vehicles were also commonly implicated in fatal injuries, with $84 \%$ of these occurring in the agricultural production sector. Of the 19 motor vehicle incidents, seven (37\%) involved overturning or being run over by all terrain vehicles. Four of the all terrain vehicles had four wheels and two had three wheels. Falls from two wheel motorbikes and horses accounted for a further two deaths each. Embankments and slopes were implicated in five $(26 \%)$ of all motor vehicle incidents.

Although uncommon in the agricultural production sector, air transport crashes were one of the main causes of death from injury for workers in the services to agriculture sector. Nine $(75 \%)$ of these fatal injuries took place while the man who died was piloting a plane, with the remaining three fatal injuries occurring when the man who died was piloting a helicopter. All of the plane crashes took place during crop dusting. In most cases it was not possible for accident investigators to determine precisely what the factors leading to the incident were.

Being struck by a falling object had the third highest rate of fatal injury for workers in the agricultural production sector, and was fourth overall. Five of the nine fatal injuries were the result of being hit by falling or rolling parts of 
Table 2 Number and rate/100000 male worker-years (95\% CI) of fatal injury by sector and incident characteristics, 1985-94

\begin{tabular}{|c|c|c|c|c|c|c|c|c|c|}
\hline & \multicolumn{3}{|c|}{ Agricultural production } & \multicolumn{3}{|c|}{ Services to agriculture } & \multicolumn{3}{|c|}{ Total } \\
\hline & $n$ & Rate & $95 \% C I$ & $n$ & Rate & $95 \% C I$ & $n$ & Rate & $95 \% C I$ \\
\hline \multicolumn{10}{|l|}{ Year: } \\
\hline 1985 & 15 & 19.9 & 11.2 to 32.9 & 1 & 16.2 & 0.4 to 90.0 & 16 & 19.6 & 11.2 to 31.9 \\
\hline 1986 & 13 & 17.8 & 9.5 to 30.4 & 1 & 17.1 & 0.4 to 95.4 & 14 & 17.7 & 9.7 to 29.8 \\
\hline 1987 & 7 & 9.9 & 4.0 to 20.4 & 7 & 127.6 & 51.3 to 262.8 & 14 & 18.3 & 10.0 to 30.8 \\
\hline 1988 & 18 & 26.2 & 15.5 to 41.4 & 4 & 77.9 & 21.2 to 199.4 & 22 & 29.8 & 18.7 to 45.1 \\
\hline 1989 & 16 & 24.1 & 13.8 to 39.1 & 2 & 41.8 & 5.1 to 151.1 & 18 & 25.3 & 16.1 to 41.7 \\
\hline 1990 & 12 & 18.7 & 9.7 to 32.6 & 2 & 45.2 & 5.5 to 163.1 & 14 & 20.4 & 11.2 to 34.2 \\
\hline 1991 & 11 & 17.7 & 8.9 to 31.7 & 0 & 0.0 & 0.0 to 90.5 & 11 & 16.6 & 8.3 to 29.8 \\
\hline 1992 & 9 & 14.5 & 6.6 to 27.5 & 3 & 67.5 & 13.9 to 197.1 & 12 & 18.0 & 9.3 to 31.5 \\
\hline 1993 & 9 & 14.4 & 6.6 to 27.4 & 5 & 103.8 & 33.7 to 242.1 & 14 & 20.8 & 11.4 to 34.9 \\
\hline 1994 & 13 & 20.8 & 11.1 to 35.5 & 4 & 77.1 & 21.0 to 197.3 & 17 & 25.1 & 14.6 to 40.2 \\
\hline \multicolumn{10}{|l|}{ Type of incident: } \\
\hline Machinery & 69 & 10.3 & 8.0 to 13.1 & 10 & 19.9 & 9.5 to 36.5 & 79 & 11.0 & 8.7 to 13.7 \\
\hline Motor vehicle & 16 & 2.4 & 1.4 to 3.9 & 3 & 6.0 & 1.2 to 17.4 & 19 & 2.6 & 1.6 to 4.1 \\
\hline Air transport & 2 & 0.3 & 0.0 to 1.1 & 10 & 19.9 & 9.5 to 36.5 & 12 & 1.7 & 0.9 to 2.9 \\
\hline Struck by falling object & 8 & 1.2 & 0.5 to 2.4 & 1 & 2.0 & 0.1 to 11.1 & 9 & 1.3 & 0.6 to 2.4 \\
\hline Electrocution & 5 & 0.7 & 0.2 to 1.7 & 2 & 4.0 & 0.5 to 14.3 & 7 & 1.0 & 0.4 to 2.0 \\
\hline Drowning & 6 & 0.9 & 0.3 to 2.0 & 0 & 0.0 & 0.0 to 7.3 & 6 & 0.8 & 0.3 to 1.8 \\
\hline Homicide & 6 & 0.9 & 0.3 to 2.0 & 0 & 0.0 & 0.0 to 7.3 & 6 & 0.8 & 0.3 to 1.8 \\
\hline Fall & 3 & 0.4 & 0.1 to 1.3 & 0 & 0.0 & 0.0 to 7.3 & 3 & 0.4 & 0.1 to 1.2 \\
\hline Nature or environment & 3 & 0.4 & 0.1 to 1.3 & 1 & 2.0 & 0.1 to 11.1 & 4 & 0.6 & 0.2 to 1.4 \\
\hline Explosion & 2 & 0.3 & 0.0 to 1.1 & 0 & 0.0 & 0.0 to 7.3 & 2 & 0.3 & 0.0 to 1.0 \\
\hline Suffocation & 1 & 0.1 & 0.0 to 0.8 & 1 & 2.0 & 0.1 to 11.1 & 2 & 0.3 & 0.0 to 1.0 \\
\hline Fire & 1 & 0.1 & 0.0 to 0.8 & 0 & 0.0 & 0.0 to 7.3 & 1 & 0.1 & 0.0 to 0.8 \\
\hline Poisoning & 0 & 0.0 & 0.0 to 0.6 & 1 & 2.0 & 0.1 to 11.1 & 1 & 0.1 & 0.0 to 0.8 \\
\hline Other & 1 & 0.1 & 0.0 to 0.8 & 0 & 0.0 & 0.0 to 7.3 & 1 & 0.1 & 0.0 to 0.8 \\
\hline \multicolumn{10}{|l|}{ Cause of death: } \\
\hline Multiple injuries & 32 & 4.8 & 3.3 to 6.8 & 15 & 29.8 & 16.7 to 49.1 & 47 & 6.5 & 4.8 to 8.7 \\
\hline Internal injury of chest, abdomen, & & & & & & & & & \\
\hline and pelvis & 25 & 3.7 & 2.4 to 5.5 & 6 & 11.9 & 4.4 to 25.9 & 31 & 4.3 & 2.9 to 6.1 \\
\hline Head injury & 19 & 2.8 & 1.7 to 4.4 & 3 & 6.0 & 1.2 to 17.4 & 22 & 3.1 & 1.9 to 4.6 \\
\hline Miscellaneous & 13 & 1.9 & 1.0 to 3.3 & 3 & 7.9 & 1.2 to 17.4 & 16 & 2.2 & 1.3 to 3.6 \\
\hline Crush asphyxia & 14 & 2.1 & 1.1 to 3.5 & 0 & 2.0 & 0.0 to 7.3 & 14 & 1.9 & 1.1 to 3.3 \\
\hline Drowning & 10 & 1.5 & 0.7 to 2.8 & 0 & 0.0 & 0.0 to 7.3 & 10 & 1.4 & 0.7 to 2.6 \\
\hline Electrocution & 6 & 0.9 & 0.3 to 2.0 & 2 & 4.0 & 0.5 to 14.3 & 8 & 1.1 & 0.5 to 2.2 \\
\hline Spinal damage & 3 & 0.4 & 0.1 to 1.3 & 0 & 0.0 & 0.0 to 7.3 & 3 & 0.4 & 0.1 to 1.2 \\
\hline Unknown & 1 & 0.1 & 0.0 to 0.8 & 0 & 0.0 & 0.0 to 7.3 & 1 & 0.1 & 0.0 to 0.8 \\
\hline
\end{tabular}

trees during tree felling activities. The remainder of the fatal injuries were being hit by a falling petrol tank, trapped in a grain spillage, crushed by silage, and hit by a falling cattle crate.

The physiological cause of death is presented in table 2. The miscellaneous category includes all causes of death where there were less than three fatal injuries during the study decade, and which did not fit naturally into one of the other categories. Burns, poisoning, aspiration of foreign materials, and pulmonary embolism are examples of these. The highest three

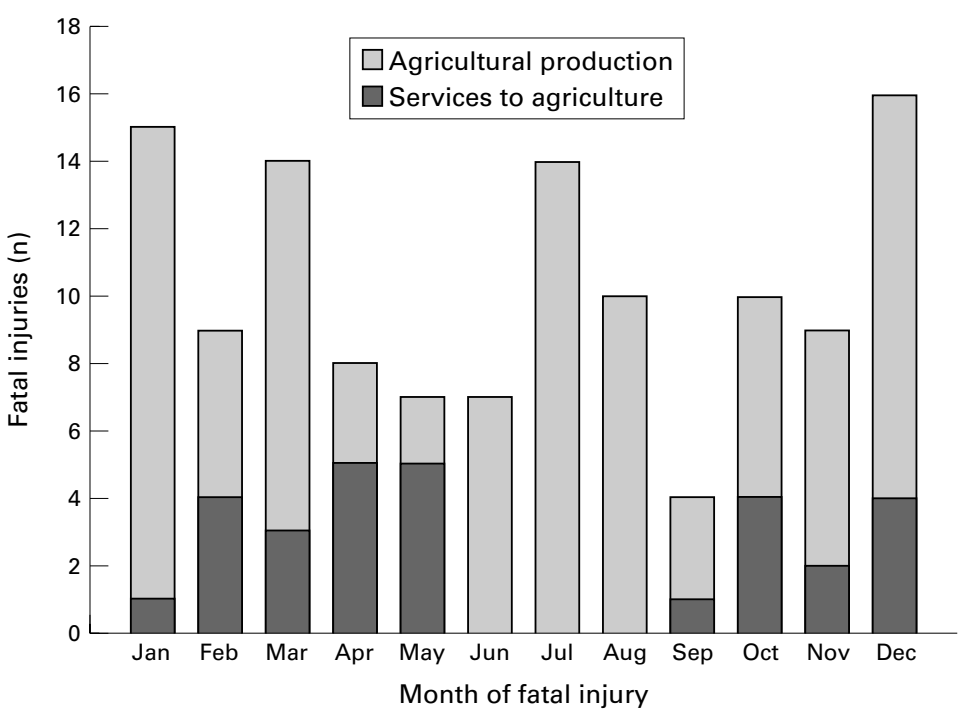

Figure 1 Number of fatal injuries by month of incident for men in agricultural production and services to agriculture, 1985-94. categories remained consistent across the sectors, with multiple injuries and internal injury of the chest, abdomen, and pelvis dominating.

Analysis of the month of fatal incident showed differences between the agricultural production and services to agriculture sectors (figure 1). Although agricultural production had peaks in fatal injuries at certain points in the year, fatal injuries in the services to agriculture sector remained fairly consistent throughout the year except for the winter months of June to August, where they disappeared. Because of the low number of deaths involved, it is difficult to determine whether the seasonal patterns found represent a robust effect or random fluctuation, or if the patterns shown in figure 1 are typical of those found in individual years.

\section{Discussion}

At 21.2, the rate of fatal injuries per 100000 male worker-years for agriculture was just over four times the combined industry rate for New Zealand. ${ }^{9}$ This result is consistent with other findings both within New Zealand and overseas, which have shown the agricultural workforce to consistently rank among the highest risk industrial sectors for fatal injury. ${ }^{3-7}$ At nearly a quarter of all work related injury deaths in New Zealand for the study period, agriculture was also a significant contributor to the overall fatal injury burden for workers, even though only $9 \%$ of the New Zealand workforce was employed in that sector. 
The results from this study raise several important issues. The most striking result is that the rate of work related fatalities across both agricultural sectors combined did not decrease over the study period. This is at odds with trends reported for other industrial sectors in New Zealand, where the overall rate of work related fatal injuries showed a generally downward trend over the same period. ${ }^{9}$ A similar situation exists in Australia, where the overall rate of fatal injuries declined over the 1982-92 period by $18 \%$, yet the rate for agriculture rose by $6 \%{ }^{5}$ By contrast, analyses in the United States by Stout et $a l^{7}$ for the 1980-9 decade indicated a substantial reduction of $37 \%$ in the overall rate of fatal injuries, with a $24 \%$ decrease in the agricultural production and services to agriculture sectors. ${ }^{15}$ Finding the reasons behind the differences in performance between these three countries may provide valuable insights for efforts to control injury in New Zealand.

Agriculture in New Zealand has been through substantial changes over the study decade as the result of deregulation and market reforms ${ }^{16}$ Coupled with the stock market crash in 1987, this may have placed extra pressure on agricultural workers as they were forced to work within tighter economic limits. Certainly, an examination of the value of agricultural outputs and the costs of inputs by Steele ${ }^{17}$ supports this view. An interesting spin off from this may have been an increase in the use of unpaid family labour to reduce costs. From 1986-91 the percentage of the agricultural production workforce classified as unpaid family labour rose slightly, before doubling in the period 1991-6. The effect that this change in the make up of the agricultural production workforce may have on fatal injuries is unclear. It does, however, provide an illustration of the dynamic nature of the agricultural sectors in New Zealand across this period, and the need for further understanding of how economic factors affect the injury experience of the agricultural workforce.

The distribution of fatal injuries across the seasons is consistent with the types of activities performed at those times, and may reflect variations in exposure to certain hazards. Services to agriculture, which is dominated by contract fertiliser spreading and harvesting, had no fatal injuries during the winter months when very few operators would be undertaking these activities. The peaks in fatal injuries for the agricultural production sector are also consistent with times of harvesting, haymaking, planting, and feeding out, ${ }^{18}$ which involve heavy use of machinery and motor vehicles. However, the few deaths from injury each year means that chance fluctuations can not be dismissed as an explanation for the distribution of deaths across the seasons.

Also of interest is the fact that there are few fatal injuries to women. Despite being $32 \%$ of the total agricultural workforce, women only accounted for $4.3 \%$ of fatal injuries. This may in part reflect the types and nature of the work women perform on farms, with women perhaps being exposed less regularly to high risk situations and working less hours than their male counterparts. ${ }^{18} 19$

The overseas experience that older agricultural workers were at greater risk of fatal injury was also found here. ${ }^{15} 1920$ Although agricultural workers in the 35-44 age group accounted for the greatest number of fatal injuries, the rate for the 65-84 age group was 2.2 times that of all other age groups combined. Fatal injuries in the older age group tended to be due to incidents with machinery. Without detailed exposure data, it is impossible to determine whether the increased rate is due to a greater use of machinery, a diminished likelihood of surviving injury, or an increased probability of an incident in the older age group.

Further investigation into the reasons for the increased risk in the 65-84 age group is therefore required. Analysis of trends in the agricultural workforce indicates that although the number of workers in this group is relatively small, the percentage of the agricultural workforce made up by workers of 65 and over is increasing. This may again be due to economic restraints forcing more farm workers to continue working beyond the retirement age of 60-65 found in other sectors, as well as an increase in the number of people retiring to run small farm units.

Machinery was involved in just over half of the fatal incidents reported here. This mirrors research in North America and Australia, which has consistently shown machinery to be the main agent leading to fatal injury. ${ }^{215} 1921$ Earlier studies in New Zealand have also highlighted the dangers of machinery to agricultural workers. ${ }^{17}{ }^{22} 23$ Also consistent with previous studies in New Zealand and overseas was the finding that overturning tractors was the single most common fatal injury event, accounting for around $23 \%$ of all deaths reported here. The level trend in fatalities from overturning tractors over the study period lends support to Steele's ${ }^{17}$ observation that these events have essentially reached a stable plateau.

Efforts to reduce fatalities from overturning tractors in New Zealand have been largely limited to occupational health and safety legislation. Before 1992 there was a statutory requirement for an approved roll over protective structure to be fitted to any tractor over $742 \mathrm{~kg}$ which was not used solely for horticultural activities. Tractors first registered before 1967 were also exempted from this requirement. In 1992 new OHS legislation was introduced, and in 1995, an amendment was added specifically exempting tractors for agricultural use from the requirement of having rollover protection fitted. Currently regulations reversing this situation are being drafted for implementation within the next 2 years.

Continuing with essentially the same legislative approach is unlikely to bring about significant reductions in fatalities from overturning tractors. Rates of inspection and enforcement in New Zealand are very low. Of the roughly 66000 farm units in New Zealand, at most 3\% of them will be visited by an occupational health and safety enforcement agent in any 
given year (Pitt, Occupational Safety and Health Service, personal communication). The chances of being caught, let alone prosecuted, for not complying with occupational health and safety legislation is therefore remote, unless a serious or fatal injury incident occurs. The state's ability to enforce occupational health and safety legislation on farms is unlikely to change in the foreseeable future. Furthermore, the inclusion of exemptions for older and lighter tractors in any future legislation will likely reduce its effectiveness. Informal evidence suggests that a significant number of tractors predating the exemption cut off are still in operation, and that these tractors are less likely to have rollover protective structures fitted. ${ }^{22}$ Research from the United States suggests that older tractors are more likely to also be lighter, which seems to increase the likelihood of them being involved in a fatal incident. ${ }^{24}$

Perhaps one of the strongest arguments against a legislative approach is financial. Forcing farm owners to potentially expensive retrospective fittings or tractor upgrades may simply not be financially viable for many of them, particularly when it is likely that those who are least likely to be able to meet the cost are also the ones still using the older tractors needing the most work. Figures released from the Ministry of Agriculture and Fisheries highlight this point. ${ }^{25}$ During the 1988-96 period, the average sheep, beef, and dairy farm often operated at a net loss. Enforcing compulsory retrospective fitting or tractor upgrades will probably be extremely unpopular at best, and may lead to farm owners cutting corners in other areas to compensate.

Increasing the percentage of tractors fitted with enclosed rollover protective structures has been shown to be effective in reducing overturn fatalities, ${ }^{26}{ }^{27}$ and in a country such as New Zealand, where land used in farming tends to be uneven, use of devices which protect automatically to prevent injury is a more logical approach than attempting to prevent overturn incidents from occurring. ${ }^{23}$ The challenge is therefore to find methods for increasing their use in a manner which is practicable to farm owners and workers. One strategy which has shown promise overseas is offering a rebate to farm owners on the price of retrospectively fitting approved rollover protective structures. An evaluation of such a scheme operated in Victoria, Australia, showed encouraging levels of uptake among the agricultural sector, while being cost-effective for the state to implement. ${ }^{28}$ No such scheme has been tested in New Zealand.

The findings presented in this paper are based on the most comprehensive data source available on work related fatal injuries in New Zealand, both in terms of case capture and data quality. However, because the WRFIS excluded fatal injuries sustained while travelling on public roads (E810-E819), these are likewise absent from the analyses performed in this paper. Other research has indicated that many of these incidents occur, ${ }^{5}$ with evidence suggesting that this may be particularly endemic in the agricultural workforce. ${ }^{29}{ }^{30}$ Without this data, we cannot reliably estimate the full scope of deaths from injury to agricultural workers, and the ability to form effective injury control measures for this potentially large group is hampered.

A further limitation of this study is the use of people employed rather than hours exposed as the denominator for the calculation of rates of fatal injury. People employed was used because no appropriate time based exposure data exists in New Zealand. Although Ruser ${ }^{31}$ found that these two methods led to broadly equivalent results for United States data, there are particular groups for whom this method of rate calculation leads to significant underestimations of their risk. This was particularly so for the 15-19 and the 65 and over age groups, which Ruser found to work substantially less hours annually than the national average. It is likely that this also holds in the agricultural sectors of New Zealand. Young workers are often employed part time or during holiday seasons. Because of a diminished capacity for physical activity, older workers are also likely to work less hours and possibly be restricted to less arduous tasks. The rates presented in this study for these age groups are therefore liable to underestimate the true risk that these workers face, possibly by a substantial margin. The implications for the targeting of injury control efforts of this underestimation for older workers are minimal, as the rate of fatal injury in this group is already much higher than for other age groups. This is not the case for the rate of fatal injury with younger workers. This group may be at higher risk than most other age groups, but they would not be highlighted as a priority for injury control measures based on the results of this study.

Despite these limitations, this study provides the most recent and comprehensive description of fatal injuries in New Zealand's agricultural sectors to date. However, further analyses are required to examine the factors leading to these deaths from injury and to identify specific points for the targeting of injury control measures, particularly in incidents involving machinery and older workers. The information required to perform these analyses is available in the WRFIS dataset, and will be presented in future papers.

The work related fatal injury study was funded by the Occupational Safety and Health Service and the Accident Rehabilitation and Compensation Insurance Corporation. We are grateful to Maureen Howard for her efforts in coding the data and to Rebbecca Lilley for comments on a draft of this paper. The New Zealand Environmental and Occupational Health Research Centre is funded by the Health Research Council of New Zealand and the Injury Prevention Research Unit is funded by the Health Research Council of New Zealand and the Accident Compensation Corporation.

1 Houghton RM, Wilson AG. Farm survey findings: prevention of injuries to farmers and farm workers. Dunedin: University of Otago Consulting Group, 1994.

2 Coury H, Kumar S, Jones E. Farm related injuries and fatalities in Alberta. International fournal of Industrial Ergonomics 1999;23:539-47.

3 Health and Safety Executive. Safety statistics bulletin 1998-9. London: Health and Safety Executive, 1999.

4 National Institute for Occupational Safety and Health. Fatal injuries to workers in the United States, 1980-9: a decade of surveillance. National profile. Cincinnati, OH: US Departsurveillance. National profile. Cincinnati, OH.
ment of Health and Human Services, 1993. 
5 National Occupational Health and Safety Commission. Work-related traumatic fatalities in Australia, 1989-92. mission, 1998 .

6 Pickett W, Brison RJ. Tractor-related injuries in Ontario Can F Public Health 1995;86:243-6.

7 Stout NA, Jenkins EL, Pizatella TJ. Occupational injury mortality rates in the United States: changes from 1980 to 1989. Am F Public Health 1996;86:73-7.

8 Cryer PC, Fleming C. A review of work-related fatal injuries in New Zealand 1975-84: numbers, rates and trends. $N Z$ Med F 1987;100:1-6.

9 Feyer A-M, Langley J, Howard M, et al. The work-related fatal injury study: numbers, rates and trends of workrelated fatal injuries in New Zealand 1985-94. N Z Med 7 2001;114:6-10.

10 Langley J, Feyer A-M, Wright C, et al. Work-related fatal injuries in New Zealand: can a work-related fatality register be established electronically which is reliable? fournal of Occupational Health and Safety: Austalia and New Zealand 2000;16:145-53.

11 National Occupational Health and Safety Commission. Type of occurrence classification system. Canberra: Australian Gov-

12 Statistics New Zealand. New Zealand standard classification of occupations. Wellington: Statistics New Zealand, 1995.

13 Statistics New Zealand. Australian and New Zealand standard industrial classification (New Zealand use). Wellington: Statistics New Zealand, 1996.

14 Armitage P, Berry G. Statistical methods in medical research, 3rd ed. Boston: Blackwell, 1994.

15 Myers JR, Hard DL. Work-related fatalities in the agricultural production and services sectors, 1980-9. Am $\mathcal{F}$ Ind Med 1995;27:51-63.

16 Press D, Newell J. New Zealand regional rural diversity part two: rural change 1986-91. Wellington: Ministry of Agriculture and Fisheries, 1994. (Report No 94/14.)

17 Steele D. Severe injuries to farmers and farm workers in New Zealand. Wellington, New Zealend: IPSO Factum: Institute Zealand. Wellington, New Zealend: IPSO Factum: Institute (Report No 38.)
18 Shaw D. The work of farming women [masters]. Hamilton: University of Waikato, 1993 .

19 Day L. Farm work related fatalities among adults in Victoria, Australia: the human cost of agriculture. Accid Anal Prev 1999;31:153-9.

20 Myers JR, Hard DL, Snyder KA, et al. Risks of fatal injuries to farm workers 55 years of age and older. Am f Ind Med 1999; (suppl 1):29-30

21 National Occupational Health and Safety Commission. Agriculture industry. Canberra: National Occupational Agriculture industry. Canberra: Nation

22 Clarke JA, Marshall SW, Langley JD, et al. Epidemiology of injuries occurring on New Zealand farms. Dunedin: Injury Prevention Research Unit, 1995. (Report No OR9.)

23 Cryer PC, Fleming C. Work-related fatal injuries on New Zealand farms. Fournal of Occupational Health and Safety: Australia and New Zealand 1989;5:21-5.

24 Myers JR, Snyder KA, Hard DL, et al. Statistics and epidemiology of tractor fatalities: a historical perspective. fournal of Agricultural Safety and Health 1998;4:95-108.

25 Ward C. A decade of $i$. Wellington: Ministry of Agriculture and Fisheries, 1996.

26 Anonymous. Effectiveness of rollover protective structures for preventing injuries associated with agricultural tractors. MMWR Morb Mortal Wkly Rep 1993;42:57-9.

27 Myers JR, Snyder KA. Roll-over protective structure use and the cost of retrofitting tractors in the United States, 1993. Fournal of Agricultural Safety and Health 1995;1:18597.

28 Day L, Rechnitzer G. Evaluation of the tractor rollover protective structure rebate scheme 1997-8. Clayton, Victoria: Monash University Accident Research Centre, 1999.

29 Langley JD. What's killing our farmers? Injury Control Bulletin 1996;16:6.

30 Merchant JA. Agricultural injuries. In: Cordes DH, Rea DF, eds. Health hazards of farming. Philadelphia: Hanley and Belfus; 1991:529-39.

31 Ruser JW. Denominator choice in the calculation of workplace fatality rates. Am f Ind Med 1998;33:151-6.

\section{Answers to multiple choice questions on Aging workers by J Ilmarinen on pages 546-552}
(1) (a) False (b) False (c) True (d) True (e) True $(f)$ False
(2) (a) True (b) True (c) True (d) True (e) True (f) True
(3) (a) False (b) True $(c)$ True $(d)$ False $(e)$ True $(f)$ True
(4) (a) False $(b)$ True $(c)$ True $(d)$ True $(e)$ True $(f)$ False
(5) (a) False (b) True (c) True (d) False (e) True $(f)$ False
(6) (a) True (b) True (c) False (d) False (e) False $(f)$ True $(g)$ True 